\title{
Dirigentes de instituições que assistem dependentes químicos no Vale do Paraíba'
}

\author{
Managers of institutions that care for drug \\ addicts in the Paraíba Valley
}

\author{
Cláudia Fabiana de JESUS² \\ Manuel Morgado REZENDE 2,3
}

\begin{abstract}
Resumo
O objetivo deste estudo foi descrever e discutir a experiência dos dirigentes de instituições que dão assistência a dependentes de drogas no Vale do Paraíba, São Paulo, Brasil. Trata-se de pesquisa qualitativa e exploratória com dez dirigentes de instituições de assistência em dependência química. Foram realizadas entrevistas semidirigidas e o material transcrito foi submetido à análise de conteúdo. Encontrou-se que há falta de profissionais especializados e de equipes interdisciplinares da área de saúde, bem como de planejamento e funcionamento das instituições. Observou-se a presença de atividades de cunho religioso pautadas pelo discurso de ajuda ao próximo e a valorização de tarefas direcionadas ao trabalho, a disciplina e a espiritualidade. Conclui-se que é importante os dirigentes de instituições que prestam atendimento a dependentes de drogas desenvolverem ou mesmo adquirirem formação para trabalhar no complexo campo da reabilitação dessa população clínica, habitualmente estigmatizada e excluída.
\end{abstract}

Unitermos: Abuso de drogas. Centros de reabilitação. Profissional da saúde. Equipe de assistência ao paciente.

\begin{abstract}
The aim of this study was to describe and to debate the experiences of some managers of institutions providing care to drug addicts in the Paraiba Valley, in the state of São Paulo, Brazil. It deals with qualitative and exploratory research using ten managers from institutions which provide care to drug addicts. Some semi-directed interviews were carried out and their transcripts were submitted for analysis. We found out that there is a lack of specialized professionals and interdisciplinary teams in the area of health as well as a lack of planning and proper operation in these institutions. We also observed the presence of religious activities predicated by homilies about helping thy neighbor and the appreciation of tasks devoted to work, discipline and spirituality. We conclude that it is very important for leaders of institutions working with drug addicts to develop or even acquire the necessary training for the complex work of rehabilitation of this clinical population, which is consistently excluded and stigmatized.
\end{abstract}

Uniterms: Drug abuse. Rehabilitation centers. Professional of health. Patient care team.

\section{VरV}

1 Artigo elaborado a partir da dissertação de C.F. JESUS, intitulada "Instituições de atendimento a toxicodependentes: experiências no Vale do Paraíba". Universidade Metodista de São Paulo, 2006. Apoio financeiro: Coordenação de Aperfeiçoamento de Pessoal de Nível Superior, protocolo no 188/04.

2 Universidade Metodista de São Paulo, Faculdade de Psicologia e Fonoaudiologia, Programa de Pós-Graduação em Psicologia da Saúde. Av. Dom Jaime de Barros Câmara, 1000, Planalto, 09895-400, São Bernardo do Campo, SP, Brasil. Correspondência para/Correspondence to: M.M. REZENDE. E-mail: $<$ manuel.rezende@ uol.com.br>.

3 Universidade de Taubaté, Departamento de Psicologia. São Paulo, SP, Brasil. 
O consumo de substâncias psicoativas é uma temática contemporânea e um problema de saúde pública. Pessini (1999) afirma que houve aumento de oferta e de procura de drogas, e também de instituições que prestam atendimento a dependentes químicos.

Os modelos de tratamento para dependentes de drogas, em geral, são procedimentos ecléticos de ações médicas, psicológicas, sociais e religiosas. Instalou-se nas últimas décadas uma panacéia de abordagens para se obter a abstinência. Para se atingir esta meta os mais variados meios vêm sendo adotados, tais como desintoxicação, com ou sem manutenção farmacológica, psicoterapia, internação psiquiátrica, clínicas especializadas, programas residenciais dirigidos por ex-dependentes, programas de narcóticos anônimos e catequização religiosa (Rezende, 2004).

Segundo Ribeiro (2004), no Brasil, boa parte dos serviços é organizada única e exclusivamente a partir do empenho e boa vontade dos seus membros. Isso acarreta serviços com potencial de atendimento limitado e desvinculado das necessidades locais, embora a organização desses serviços siga manuais e diretrizes.

O estudo de causas de abandono do tratamento da dependência de drogas tem sido considerado um aspecto muito importante na avaliação da efetividade da intervenção, pois a adesão é comprovadamente um fator de sucesso do tratamento (Marques, Buscatti \& Formigoni, 2002).

Pesquisas em intervenções de caráter qualitativo que procuram entender o uso de substâncias psicoativas, ou mesmo a maior ou menor popularidade de intervenções terapêuticas e preventivas sob a ótica cultural de diferentes grupos sociais, são muito escassas. A inexistência de pesquisas qualitativas sobre drogas no Brasil é notável (Carlini-Cotrim, 1996).

A avaliação de tratamentos tem grande importância, pois não há uma modalidade terapêutica que seja superior a outra, e também há um grande número de técnicas propostas no campo literário. Na avaliação do tratamento há diferentes aspectos que podem ser verificados como benefício para os pacientes e para a comunidade, como a satisfação dos próprios pacientes, a abstinência, o custo, a abrangência em relação a diferentes tipos de pacientes, entre outros (Castel \& Formigoni, 1999).
Bucher, Fares, Pelegrini e Carmo (1995) citam que a avaliação dos atendimentos de usuários de drogas suscita numerosas dificuldades decorrentes das diversidades de abordagens e da falta de critérios unívocos. Frisa-se a necessidade de completar os critérios quantitativos com outros qualitativos para apreender as variáveis dos processos de mudanças e analisar as taxas de "recuperação".

Este estudo visou retratar a experiência e o modo de trabalho dos responsáveis pelas instituições de atendimento a dependentes químicos nas cidades de Pindamonhangaba, Taubaté e Caçapava, no estado de São Paulo.

Verificou-se, por meio do levantamento realizado, que há um considerável número de publicações. No entanto, no banco de dados da Scientific Electronic Library On Line (SCIELO), da Literatura Latino-Americana e do Caribe em Ciências da Saúde (LILACS), do Centro Brasileiro de Informações sobre Drogas Psicotrópicas (CEBRID), da Biblioteca Virtual em Saúde (BVS) e da National Library of Medicine (MEDLINE/ Pubmed), há um predomínio de pesquisas com enfoque epidemiológico e um número menor de estudos sobre tratamento em dependência de drogas com enfoque qualitativo (Jesus, 2006).

Verifica-se a importância de estudos sobre instituições de tratamento em dependência de drogas para conhecer a modalidade de intervenção, os resultados obtidos e a avaliação sistemática dos recursos teóricos e técnicos utilizados pelas instituições para discutir as intervenções. Além disso, por meio do levantamento de fontes científicas, há escassas pesquisas enfocando os responsáveis pelas instituições que dão assistência a dependentes químicos. Assim os objetivos deste trabalho foram: 1) descrever o perfil dos dirigentes das instituições que atuam em dependência química; 2) investigar a definição de dependência de drogas; 3) descrever as propostas de intervenção; 4) descrever os critérios de admissão, adesão e alta; 5) obter informações sobre os critérios de avaliação de resultados; e 6) levantar fatores de promoção de saúde.

\section{Método}

Tratou-se de um estudo qualitativo, de caráter exploratório. O instrumento de coleta de dados foi uma 
entrevista semidirigida com questões abertas que, teoricamente, assegura possibilidades indefinidas de aprofundamento dos entrevistados no tema. Foram propostos aos entrevistados temas gerais, como "Histórico da Instituição" e "Experiência do dirigente naquela instituição de atendimento a dependentes químicos". Posteriormente, foram levantadas algumas questões acerca dos objetivos específicos, caso o entrevistado não tivesse respondido nos temas gerais.

Foram mapeadas as instituições que atuam na área de dependência de drogas por meio de levantamento feito a partir dos órgãos públicos, particulares e oficiais das cidades escolhidas para esta pesquisa. As instituições foram selecionadas a partir de um dos dois critérios adotados em relação aos serviços oferecidos nas três cidades do Vale do Paraíba. O primeiro critério inclui os serviços oferecidos, registrados e filiados pela Federação Brasileira de Comunidades Terapêuticas (FEBRACT) e pela Agência Nacional de Vigilância Sanitária (ANVISA). O segundo critério considera os serviços oferecidos indicados pelas prefeituras, secretarias de saúde, assistência social e saúde mental dessas cidades.

As cidades escolhidas para o estudo foram por amostra de conveniência. Optou-se, em primeiro plano, pela inclusão das instituições de atendimento das cidades de Pindamonhangaba, Taubaté e Caçapava devido à facilidade geográfica de acesso às instituições. Em segundo plano, a escolha das cidades ocorreu por elas se situarem ao redor da Universidade de Taubaté (UNITAU), que forma profissionais da área de saúde uma vez que oferece cursos de Psicologia, Serviço Social, Biologia, Enfermagem, Fisioterapia, Educação Física e Medicina.

Foi selecionada também uma instituição que não está entre as três cidades citadas, já que tem sua sede na cidade de Guaratinguetá, interior do estado de São Paulo. Ela foi escolhida por ser uma das instituições da área com maior tempo de funcionamento, além de ser registrada pela FEBRACT.

As entrevistas com os dirigentes foram realizadas nas próprias sedes das instituições: uma em Pindamonhangaba, uma em Guaratinguetá, três em Caçapava e cinco em Taubaté. Pontua-se que a definição do conceito de dirigente refere-se ao responsável pela instituição.
De forma geral, a entrevista conta com uma primeira parte, que se refere ao histórico e à experiência do dirigente da instituição, e com uma segunda parte, que apresenta informações que não são abordadas durante a comunicação aberta e espontânea.

O trabalho teve como base o método de análise de conteúdo a partir de Bardin (1977).

\section{Resultados e Discussão}

A amostra configurou-se heterogênea e seus componentes diversificaram-se quanto a variáveis sócio-demográficas.

Observa-se que a idade mínima foi 26 anos, a idade máxima foi 65 anos e a média em anos foi 42,2 anos. Predominou o sexo masculino; dentre estes, metade era casada.

Dois dos entrevistados apresentaram nível de escolaridade do Ensino Fundamental. Pontua-se o baixo nível de escolaridade dos dirigentes dessas instituições de atendimento a dependentes químicos.

As profissões dos dirigentes das instituições são variáveis. Verificou-se que 30\% dos entrevistados eram profissionais da área de saúde e, entre estes, nenhum tinha formação em dependência química.

Certificou-se que 50\% dos responsáveis pelas instituições eram ex-dependentes e $80 \%$ das instituições tinham a presença de ex-dependente na equipe.

Observou-se que em 70\% das instituições os dirigentes apresentaram tempo de experiência de uma dez anos. Dois dirigentes apresentaram tempo de experiência de vinte a vinte e um anos.

Notou-se um menor número de técnicos da área de saúde nas instituições de atendimento a dependentes químicos, em comparação a pessoas do setor religioso e ex-dependentes. Para Laranjeira (1996) e Tancredi, Barrios e Ferreira (1998), boa parte dos serviços em atendimento a dependentes químicos é organizada exclusivamente com a boa vontade, sem uma equipe preparada, e apresenta disponibilidade de atendimento limitada.

Identifica-se que há poucos profissionais com formação em dependência química e habilitados a trabalhar com essa demanda. Galduróz e Carlini (1993) 
afirmam que, no tratamento de dependência de drogas, é importante que profissionais capacitados saibam lidar com as recaídas e motivem o paciente.

\section{Características conceituais}

As características conceituais são citadas a partir do referencial dos dirigentes.

\section{Definição de dependência de substâncias psicoativas}

A maioria dos dirigentes citou a dependência química como uma doença. Alguns dirigentes citaram a doença como algo curável e outros como algo incurável. Outro conceito para definir a dependência química foi "falta de caráter", e um dirigente citou a expressão "falta de amor". Observa-se que a definição de dependência de drogas se referiu a 70\% como doença e, desse total, 40\% citou como doença incurável. Verificase que, na definição de doença, o sujeito é visto de uma maneira determinista e fatalista, com pouco ou nenhum controle sobre o que lhe acontece.

A dependência é uma doença e o psicológico da pessoa estáabalado. A dependência iráacompanhá-lo sempre.

A drogaéuma doença. Odrogadoéum doentequepode ser recuperado. Tem a possibilidade de ser curado, sarado, transformado. Nós convertemos pelaigreja; nós curamos.

Ele precisa ter bastante consciência que essa doença não tem cura, então, mesmo nós que somos evangélicos, a ciência prova que não tem cura, e nós que somos evangélicos cremos em Deus, que Deus liberta, mas que nãocura.

Compreendemos a dependência química como a organização mundial da saúde diz: é uma doença que não tem cura, que a pessoa ficará em recuperação a vida toda.

Eu acho que todo dependente, pelos que passaram por aqui, tem o seu caráter deformado.

Dependente químico!. Um cara que não tem caráter, não tem personalidade. O caráter dele domina.

A definição da dependência como falta de caráter possibilita a reflexão sobre a moralidade associada a um comportamento desviado, como um desvio de norma, comportamento esse que deve ser disciplinado, "consertado", alterado para um comportamento socialmente aceito, diferentemente, por exemplo, da definição de que a dependência vem da carência de amor. Essa forma de situar a dependência de drogas como doença e como falta de caráter refere-se ao modelo cartesiano, que considera a cura voltada para aquilo que está desviante, fora da norma. Nessa visão, a doença é equivalente à reparação de uma máquina.

Diante das entrevistas realizadas com os dirigentes não houve nenhuma citação de dependência química como sintoma. Olivestein (1980) considera o abuso de drogas um sintoma implícito, com um significado, e que representa os eventos dolorosos da vida do toxicômano.

Já Silveira Filho (1995) considera o toxicômano aquele que, sem a droga, não consegue viver, ou seja, que não consegue mudar ou se adaptar diante de uma realidade e de uma subjetividade intolerável. Para o autor, a toxicomania é uma alternativa diante da impotência completa frente a uma realidade insuportável e o sujeito busca uma mudança de percepção dessa realidade por meio da droga.

Para Olivestein (1985), no tratamento de dependentes químicos deve-se evitar o funcionamento mecânico do pensamento e a racionalização dos comportamentos. Pode-se pensar no trabalho a partir de uma prática que tenha em vista uma mudança no psiquismo. O que se observa, na maioria das instituições, é justamente a padronização de comportamentos, propondose uma mecanização na maneira de pensar.

A partir da leitura de Bucher e Costa (1985) compreende-se que os tratamentos em dependência de drogas passam por várias limitações, como a diversidade das substâncias consumidas, a heterogeneidade dos dependentes, as dificuldades no próprio tratamento, entre outras. Assim, percebe-se que essa complexidade pontuada pelo campo científico não foi levantada significativamente pelos dirigentes.

O modelo biológico de doença pressupõe que o consumo de drogas, quanto ao aspecto de abuso e dependência, determina uma doença crônica, progressiva e fatal. Esse modelo é passível de críticas por basear-se em modelos genéticos controvertidos e totalitários, além de não abranger todos os casos (Silveira Filho, 1996). 


\section{Modos de intervenção das instituições}

Em relação à forma de trabalho, 40\% das instituições apresentam religião e trabalho (laborterapia), $30 \%$ das instituições apresentam regras disciplinares, doze passos e terapia individual, 20\% das instituições apresentam convivência em grupo, terapia ocupacional, terapia em grupo, oficinas, atendimento psiquiátrico e orientação familiar, e 10\% apresentam palestras de motivação e relaxamento.

Nas instituições que têm na equipe profissionais da área de saúde, verifica-se que há o trabalho de psicoterapia, seja individual ou em grupo, diferentemente daquelas nas quais não há profissionais desta área. Observa-se que os dirigentes que não têm formação técnica adotam a implantação da religião e/ou do trabalho manual e impõem uma rotina diária como critério de aprendizagem de disciplina. Estes, segundo os dirigentes, são procedimentos que"tratam"do dependente de drogas.

Pontua-se que o modo de intervenção não apresenta trabalho de cunho técnico-científico e salienta-se que 70\% das instituições não têm profissionais da área de saúde. Pelo discurso dos dirigentes, não há um referencial teórico que dê embasamento para suas práticas e metodologias de trabalho.

O tratamento seria começar a ser trabalhado o caráter dele, todo caráter dele, que está deformado. Então, ele precisa voltar a aprender a respeitar normas, regras, que nós temos que obedecer em qualquer lugar. Eles vêm faltando isso...

Precisam ter horário para levantar, para participar da oração, ter que obedecer e cuidar do trabalho da cozinha, do banheiro, do alojamento... . Tem que fazer as coisas com ordem.

Trabalha-se com espiritualidade, convivência com grupo etrabalho.

Étrabalhada a disciplina, as boas maneiras com eles, toda essa educação.

A gente trabalha a dependência química baseada nos Doze Passos dos alcoólatras anônimos, e, é claro, com uso de outras drogas, e aí a gente vai pelo N.A..

O tratamento é pelo trabalho, pela transformação espiritual. É fazer com que a pessoa volte a ter uma vida com regras, ser disciplinada e ser digna de novo... . O objetivo aqui é libertar as pessoas. A gente é como um tesourão, que vai cortando, cortando os galhos ruins, secos.

Observa-se que grande parte das instituições estabelece uma rotina regida por regras e normas que o indivíduo deve seguir.

Laranjeira et al. (2003) afirmam que, na assistência em dependência de substâncias psicoativas, indicamse técnicas psicoterápicas, entrevistas motivacionais, intervenção breve, prevenção de recaída e terapia cognitivo-comportamental, porém essas indicações são escassamente realizadas nas instituições pesquisadas.

Percebe-se também como instrumento terapêutico a convivência entre os internos, pois compartilham vivências comuns que se estabelecem como uma rede de apoio. Ressalta-se que o tratamento busca resgatar a rotina baseado em um programa diário de atividades, tarefas etc. Os dirigentes das instituições pontuam que visam à ocupação do tempo do interno, fazendo com que ele evite pensar na droga e ter comportamentos associados ao uso e, assim, mantêm o ex-dependente na produtividade e na participação das atividades e afazeres, como eles mesmos definem.

\section{Critérios de admissão, adesão e alta}

A admissão está ligada a 60\% de casos com quadro de dependência química nas instituições. Contudo, não se segue um critério especializado de diagnóstico para dependência química, pois não há profissionais habilitados para realizar esse diagnóstico.

O critério de admissão está ligado àqueles que querem uma nova vida...

O critério de admissão é sem limite. Uma pessoa com questões particulares ou diferentes pode vir sim, se tem barreira para entrar, a gentefaz de tudo para ajudar. Não dispensamos a pessoa que quer ajuda. O importanteé ela querer mudar de vida. Admitimos qualquer pessoa que queira deixar esse mundo das drogas, do crime, da prostituição.

A adesão ao tratamento é citada pelos dirigentes de maneira bastante diversificada. O fator que foi mais pontuado foi o interesse do usuário pelo tratamento, posteriormente, citaram o fator idade, família e religião.

Um total de 70\% das instituições cita a adesão como a responsabilidade do usuário e da família, e não se pontua a própria responsabilidade no processo de 
adesão do usuário que abusa de drogas. A adesão ao tratamento está relacionada significativamente à vontade do indivíduo, como é colocado pelos entrevistados.

O indivíduo que fica, que adere ao tratamento, éporque quer, tem boa vontade, segue o que falamos, esse adere.

Adere ao tratamento aquele que vem por ele mesmo, que vem com vontade de mudar de vida, que coopera... quem se volta para o lado espiritual também fica mais tempo no tratamento... Quem adere realmente ao tratamento tem a ver com quem assume o tratamento.

Aderem os que estão mais envolvidos com as próprias mudanças.

Para o responsável, aquele que adere ao tratamento é quem deseja realmente parar com o uso e isso representa toda a responsabilidade que se volta para o próprio indivíduo.

As posições em relação ao tratamento de drogas parecem ser controversas. Há estudos que apontam a baixa relação entre o grau da dependência e o prognóstico. Verifica-se uma falta de consenso entre as estimativas fornecidas por profissionais e por pacientes sobre o grau da dependência e as possibilidades de recuperação. Contudo, a dificuldade não está no agravamento do dependente de drogas, mas nos fatores contextuais (Andreatini, Galduróz \& Formigoni, 1994). Identifica-se carência de relatos e discussões a respeito dos fatores contextuais e, segundo os entrevistados, há a ênfase da intensidade do uso e do tipo de droga utilizada.

A alta do tratamento realizado pelas instituições, em 70\% dos casos, está relacionada ao término do programa proposto. Assim, pontua-se que há pouca ou nenhuma consideração por outras variáveis no processo de alta.

A altaébaseada na programação cumprida. A alta segue a programação

A alta estáligada ao tratamento de um ano, ou seja, após esse tempo, tem alta.

Em relação à alta, há sim. Na verdade, o tratamento tem por no mínimo seis meses. Terminado esse tempo ele recebe a alta.

Em relação à alta, que, para os entrevistados, diz respeito à capacidade de o indivíduo sair do tratamento em abstinência e retomar sua vida, sete dirigentes citaram que está ligada ao término do programa proposto.
Isso quer dizer que o indivíduo precisa finalizar esse período para poder receber esse aval do dirigente relatando que o indivíduo está pronto para sair. Os internos devem "fazer por merecer"sua alta, que consiste, na realidade, em cumprir o programa ditado pela instituição, aprendendo a se submeter a regras e normas de uma rotina rígida.

Verifica-se, nesse caso, uma ausência de discussões sobre outros fatores ligados ao processo do tratamento. Indaga-se o que se espera do resultado do tratamento e acredita-se que a alta fica ligada mais à questão da abstinência do que a outras mudanças. A maioria dos responsáveis pelas instituições discute "alta" como o término do tratamento, com a programação cumprida.

De acordo com Kerr-Corrêa, Lima, Dalben e Hegedus (1999), o tratamento na dependência de drogas deve ser visto a partir da natureza crônica recorrente desses transtornos, e não em termos de cura e não cura. Para os autores, na análise da literatura atual, não há como negar a complexidade dos mecanismos de dependência de drogas, além da variação nas abordagens. Percebe-se que o "tratamento" realizado pelos dirigentes, em sua maioria, só existe a partir de uma via, a da instituição. Demonstra-se como um padrão igual para todos, e o seguimento do programa, supostamente, garante a alta. Não se levanta nem se discute a participação dos indivíduos em seu próprio tratamento, ou seja, seu envolvimento, seu interesse e sua responsabilidade diante da própria dependência são considerados normalmente pouco relevantes.

Os resultados do estudo de Marques, Buscatti e Formigoni (2002) demonstram a importância de desmistificar o tratamento. É necessário esclarecer a função do terapeuta responsável pela instituição e a responsabilidade do paciente pela própria mudança, assim como introduzir técnicas de prevenção de recaída, para possibilitar o aumento de adesão ao tratamento. No entanto, essas estratégias não foram citadas pelos dirigentes.

O desligamento ocorre em 80\% das instituições pesquisadas quando há quebra de normas, uso de drogas e violência.

Deixamos muito claro as regrase as normas.... Esealguma regrafor quebrada, poderá havero desligamento. 
Há sim exclusão, desligamento do tratamento, se tiver agressividade, violência, se pegar com drogas e, dentro disso, temos as advertências para que a pessoa possa retomar a linha, a disciplina.

\section{Avaliação de resultados}

A percepção de melhora do usuário diz respeito ao comportamento. Em nenhuma instituição há uma avaliação de resultados de maneira padronizada e sistematizada.

Há avaliação aqui dentro, há um resultado, porquevocê vê a mudança de caráter, de personalidade, que a pessoa muda, está ali visível diante da gente.

A avaliação de resultados évisivel porque a gente percebe no olhar, no jeito, no semblante da pessoa.... Chega com a cara fechada, agressivo e, com o tempo, a gente vai percebendo aqueles que vão aderindo à alegria, novo jeito deveras coisas.

A avaliação é vista, é percebida no dia-a-dia, na convivência com eles.

A gente não tem avaliação de resultado... Até não tinha pensado nisso. Avaliamos aquidentro... Avaliamos pelo comportamento dele, aquele que faz o tratamento inteiro

A avaliação é feita no dia-a-dia, por meio do comportamento deles. O certificado é uma prova do resultado dele aqui.

Verifica-se na pesquisa que não há uma preocupação em avaliar os resultados do atendimento proposto aos usuários dos serviços. Neumann et al. (1992), em relação ao tratamento de toxicômanos, enfatizam que dependendo do critério de sucesso ou fracasso adotado as conclusões podem ser diferentes. Por meio desses estudos, observa-se cada vez mais a necessidade de conhecer e avaliar os tratamentos em dependência de drogas, pois não é realizada a avaliação da eficácia do atendimento. Os entrevistados comentam que, nas instituições pesquisadas, não há dados sistematizados em relação à desistência e ao abandono do atendimento.

Para discutir sobre avaliação do tratamento em dependência de drogas é necessário realizar o diagnóstico segundo dados do CID-10 ou DSM-IV TR, para ter critérios sistematizados, ao invés de uso inadequado de conceitos, pré-julgamentos e estereótipos.

\section{Promoção de saúde}

Observa-se que 90\% das instituições pesquisadas (nove) citam que a promoção de saúde em seu trabalho está relacionada à saúde física. Há, também, outros fatores citados, como a saúde psíquica, o trabalho, a religiosidade, a readaptação à rotina, a reinserção social e as artes.

Opessoalentra aquimuito mal, com a saúde prejudicada, não tem horário para comer, e em pouco tempo está com a saúde recuperada. Assim, voltam a ter rotina, com disciplina. Eles também têm uma mudança espiritual.

Eles têm horário, têm rotina. Lá fora não têm regra para comer, para dormir, para nada. Vamos colocar no padrão do homem certo, no lugar, com disciplina e com hora para tudo. Elecuida do corpo, ele passa a ficarmelhor, o seu corpo, o físico.

A gente promove saúde aqui. Eles têm várias refeições durante o dia, em cada intervalo tem frutas, eles comem à vontade... . A gente os leva ao médico, a gente marca. A gente tem acesso lá. Muitos aqui tinham tuberculose, pneumonia, doença na bexiga, eforam curados.

A promoção de saúde, de maneira geral, está ligada às necessidades mais primárias, como a retomada de uma boa alimentação e do sono, o restabelecimento físico, a adaptação a uma nova rotina e às regras, além da abstinência e da desintoxicação. Assim, essas instituições, de alguma maneira, valorizam alguns fatores que promovem qualidade de vida aos usuários.

De acordo com Laranjeira (1996), existe uma grande diversidade de questões envolvidas na dependência de drogas. Por haver, também, uma diversidade de população envolvida, demonstra-se a importância de se estabelecer redes de serviço que sejam também diferenciadas, e que, de alguma forma, encontrem ações que minimizem os efeitos e conseqüências do uso indevido destas substâncias.

Verifica-se que, embora com poucos recursos em várias áreas, os dirigentes citam alguns fatores que promovem a saúde dos pacientes. Segundo Pais Ribeiro (1998), no campo da saúde surge a busca de alterar o estilo de vida da população, como a mudança de alguns comportamentos, entre eles: cuidar da alimentação, deixar de fumar, controlar o estresse, praticar exercícios físicos, criar meios para recrear e descansar, entre outros. 
As instituições pesquisadas promovem saúde de alguma forma, porém o desenvolvimento da responsabilidade diante da própria vida, das escolhas, da saúde e da doença apresenta-se muito escasso. Pela fala dos entrevistados, verifica-se que a instituição está voltada para a função de controle social e de imposição de limites.

Goffmann (1974) utiliza o termo "instituições totais" para designar casos em que ocorre progressivamente um afastamento dos direitos que o indivíduo usufruía livremente em seu mundo externo, caracterizando uma ruptura inicial com os papéis anteriores para assumir o papel de internado. Observa-se que nestas instituições, os internos levam a vida formalmente administrada e controlada, bem como há reprodução de estigmas e de exclusão social dentro das próprias instituições.

Bleger (1992) considera que a instituição não é somente um instrumento de regulação, normatização, controle social ou de saúde, mas também pode ser um espaço que cristaliza valores e crenças que reforçam a resistência a mudanças. Muitas vezes, podem-se tornar depositárias de sistemas de defesa frente às ansiedades e fontes de alienação. Para Foucault (1996), os mecanismos disciplinares adotados nas instituições, como forma de controle de todas as atividades, configuramse como um poder que tem a função de moldar e adestrar.

Pelo discurso dos entrevistados, observa-se a instituição como uma maneira de regulação de normas e condutas a serem seguidas pelos usuários, ou seja, como uma forma de instituir limites que os usuários "buscam"encontrar. O espaço de diálogo é restrito e há pouca possibilidade de se trabalhar a singularidade.

\section{Considerações Finais}

De acordo com os entrevistados, as instituições pesquisadas não recebem apoio das prefeituras e dos órgãos oficiais e, mesmo com dificuldades financeiras e falta de recursos, seja de profissionais qualificados ou de estrutura física, elas acolhem essa demanda a partir de seu referencial de dependência química e do que seja "tratamento". Contudo, de certa maneira, promovem saúde, mesmo que sejam cuidados primários, como alimentação, higiene, sono e readaptação a uma rotina diária. É possível supor que os usuários de drogas optem ou permaneçam nessas instituições devido à falta de outros recursos, aliada às dificuldades financeiras.

Há uma grande ênfase dada às pessoas que já vivenciaram situações com as drogas, como se somente elas pudessem ensinar algo nessa área, por já terem vivido. Nota-se isso no discurso dos ex-dependentes entrevistados, que acreditam que, para trabalhar com dependentes químicos, a pessoa mais indicada seria aquela que já passou por essa experiência, ou seja, um ex-dependente em recuperação.

Verifica-se nos entrevistados das instituições um discurso dominante, tradicional, centrado no modelo de abstinência, de controle social e de sua segregação como, simplesmente, doentes, e isso caracteriza grande parte das práticas na região estudada. A dificuldade de encontrar uma definição sobre o que é saúde e doença, o que é "normal" e o que é "anormal", faz com que as instituições sejam também determinantes de normas de marginalização e de exclusão de determinados setores.

Predominou nos participantes deste estudo a concepção de que o usuário de droga deva entrar para o atendimento na instituição e assumir a seguinte posição: "eu sou um dependente de drogas", e sair do atendimento com a mesma posição, porém sem o uso da droga. Admite-se a impossibilidade da cura, assim, não há alternativa, ou então há a cura por meio da conversão religiosa.

As instituições não têm uma equipe interdisciplinar e não há um seguimento sistemático e avaliação objetiva de resultados do trabalho realizado.

A região do Vale do Paraíba é economicamente favorecida, com instituições de ensino superior atuantes, e os serviços na área de dependência química poderiam, inclusive, fazer parcerias e aproveitar os recursos humanos por elas formados.

Pontua-se a importância de os dirigentes de instituições que atendem dependentes de drogas desenvolverem ou mesmo adquirirem formação profissional e atualização científica para trabalhar no complexo campo da reabilitação dessa população clínica, habitualmente estigmatizada e excluída. Deste modo, o desejo de ajudar poderá ser mais bem iluminado pela 
reflexão crítica dos processos psi-cossociais, psicopatológicos e ideológicos que norteiam as suas práticas nas instituições.

\section{Referências}

American Psychiatric Association. (2002). Manual diagnóstico e estatístico de transtornos mentais-DSM-IV-TR. Porto Alegre: Artes Médicas.

Andreatini, R., Galduróz, J. C. F., \& Formigoni, M. L. O. S. (1994). Estudo da influência dos níveis de dependência e consumo n-a resposta ao tratamento de dependentes de álcool. Revista ABP-APAL, 16 (1), 25-29.

Bardin, L. (1979). Análise de conteúdo. Lisboa: Edições 70.

Bleger, J. (1989). Temas de psicologia: entrevista e grupos. São Paulo: Martins Fontes.

Bleger, J. (1992). Psico-higiene e psicologia institucional. Porto Alegre: Artes Médicas.

Bucher, R. E., \& Costa, P. F. (1985). A abordagem terapêutica do toxicômano. Acta Psiquiatria, Psicologia da América Latina, 31 (2), 113-130.

Bucher, R., Fares, A. T., Pelegrini, R., Oliveira, R. M., \& Carmo, R. A. (1995). A avaliação qualitativa dos atendimentos a usuários de drogas. Revista ABP-APAL, 17 (2), 75-86.

Castel, S., \& Formigoni, M. L. O. S. (1999). Escalas para avaliação de tratamentos de dependência de álcool e outras drogas. Revista de Psiquiatria Clínica, 26 (1), 32-37.

Carlini-Cotrim, B. (1996). Potencialidades da técnica qualitativa grupo focal em investigações sobre abuso de substâncias. Revista de Saúde Pública, 30 (3), 285 -93.

Foucault, M. (1996). Vigiar e punir: história da violência nas prisões. Petrópolis: Vozes.

Galduróz, J. C. F., \& Carlini, E. A. (1993). Avaliação clínica e tratamento da dependência de drogas. In F. C. Prado, J. A. Ramos \& J. R. Valle (Orgs.), Atualização terapêutica (pp.1184-1188). Porto Alegre: Artes Médicas.

Goffmann, E. (1974). Manicômios, prisões e conventos. São Paulo: Perspectiva.

Jesus, C. F. (2006). Instituições de atendimento a toxicodependentes: experiências no vale do Paraíba. Dissertação de mestrado não-publicada, Universidade Metodista de São Paulo, São Bernardo do Campo.

Kerr-Côrrea, F., Lima, M. E. C., Dalben, I., \& Hegedus, A. M. (1999). A importância da gravidade da dependência e do gênero para a evolução de dependentes de drogas. Revista ABEAD, 2 (1), 21 - 42.
Laranjeira, R. (1996). Bases para uma política de tratamentos dos problemas relacionados ao álcool e outras drogas no Estado de São Paulo. Jornal Brasileiro de Psiquiatria, 45 (4), 191-199.

Laranjeira, R., Alves, H. N. P., Araújo, M. R., Baltieri, D. A., Bernardo, W. M., \& Castro, L. A. G. P. (2003). Usuários de substâncias psicoativas: abordagem, diagnóstico e tratamento [mimeografado]. São Paulo: Conselho Regional de Medicina de São Paulo/ Associação Médica Brasileira.

Marques, A. C. P. R., Buscatti, D., \& Formigoni, M. L. O. S. (2002). O abandono no tratamento da dependência de álcool e outras drogas: como diminuir este fenômeno? Jornal Brasileiro de Dependência Química, 3 (1), 17-23.

Neumann, B. R. G. (1992). Avaliação crítica da primeira experiência de aplicação da intervenção breve no Brasil. In M. L. S. Formigoni. A intervenção breve na dependência de drogas: a experiência brasileira (pp.119-141). São Paulo: Contexto.

Olievestein, C. (1980). A droga: drogas e toxicômanos. São Paulo: Editora Brasiliense.

Olievestein, C. (1985). Destino do toxicômano. São Paulo: Almed.

Pais Ribeiro, J. L. (1998). Psicologia e saúde. Lisboa: ISPA.

Pessini, L. (1999). Drogas: o holocausto silencioso. O Mundo da Saúde, 23 (1), 3-4.

Rezende, M. M. (2004). Centros universitários de atenção à toxicodependentes, cidade de São Paulo. Actas do $5^{\circ}$ Congresso Nacional de Psicologia da Saúde (pp.809-814). Lisboa.

Ribeiro, M. (2004). Organização de serviços para o tratamento da dependência do álcool. Revista Brasileira de Psiquiatria, 26 (1), 59-62.

Silveira Filho, D. X. (1995). Drogas: uma compreensão psicodinâmica das farmacodependências. São Paulo: Casa do Psicólogo.

Silveira Filho, D. X. (1996). Alguns aspectos psicodinâmicos no tratamento da toxicomania, São Paulo. Boletim de Psiquiatria, 19 (1/2), 1-36.

Tancredi, F. B., Barrios, S. R. L., \& Ferreira, J. H. G. (1998). Planejamento em Saúde. São Paulo: IDS-USP-Itaú. Recuperado em agosto 8, 2005, disponível em htpp:// ids-saude.uol.com.br/SaudeCidadania/ed_02/ index.html

Recebido em: 30/10/2006

Versão final reapresentada em: 7/5/2007

Aprovado em: 31/7/2007 